\title{
The efficacy of Roxadustat for the treatment of anemia in dialysis dependent chronic kidney disease patients: an updated systematic review and meta-analysis of randomized clinical trials
}

\author{
Basel Abdelazeem $^{1,2} \wedge$, Kirellos Said Abbas ${ }^{3} \wedge$, Joseph Shehata ${ }^{4} \wedge$, Nahla Ahmed El-Shahat ${ }^{5}$, Nischit Baral ${ }^{6}$, \\ Pramod Savarapu $^{7 \wedge}$, Arvind Kunadi ${ }^{8}$ \\ ${ }^{1}$ Department of Internal Medicine, McLaren Health Care, Flint, MI, USA; ${ }^{2}$ Michigan State University, Flint, MI, USA; ${ }^{3}$ Faculty of Medicine, \\ Alexandria University, Alexandria, Egypt; ${ }^{4}$ Faculty of Medicine, Cairo University, Cairo, Egypt; ${ }^{5}$ Faculty of Medicine for Girls, Al-Azher University, \\ Cairo, Egypt; ${ }^{6}$ Internal Medicine Department, McLaren Health Care, Flint, MI, USA; ${ }^{7}$ Internal Medicine Department, Louisiana State University \\ Health Sciences Center, Monroe, LA, USA; ${ }^{8}$ Nephrology Department, McLaren Health Care, Flint, MI, USA \\ Contributions: (I) Conception and design: B Abdelazeem; (II) Administrative support: N Baral, P Savarapu; (III) Provision of study materials or \\ patients: J Shehata, KS Abbas, PS, N Baral, NA El-Shahat, A Kunadi; (IV) Collection and assembly of data: J Shehata, KS Abbas, NA El-Shahat, \\ A Kunadi; (V) Data analysis and interpretation: B Abdelazeem, KS Abbas, A Kunadi; (VI) Manuscript writing: All authors; (VII) Final approval of \\ manuscript: All authors. \\ Correspondence to: Basel Abdelazeem, MD. McLaren Health Care, Flint, MI, USA; Michigan State University, Flint, MI, USA. \\ Email: baselelramly@gmail.com.
}

\begin{abstract}
Background: Anemia is a common complication in chronic kidney disease (CKD) with increased morbidity and mortality. Recently published RCTs were conducted to compare the effect of the new medication roxadustat $(\mathrm{ROX})$ with erythropoiesis-stimulating agent (ESA) in dialysis-dependent CKD (DD-CKD) patients. Our article aimed to meta-analyze published RCTs to investigate the efficacy and safety of ROX for anemia in DD-CKD patients and update the effect of the new studies on overall analysis with subsequent impact on management.

Methods: Electronic databases (PubMed, EMBASE, Scopus, Web of Science, Cochrane Central, and Google Scholar) were searched systematically from inception to July 2021 by using this search term (Roxadustat OR ASP1517 OR FG4592 OR “FG-4592”) AND (kidney OR renal) AND (Anemia). We only included randomized control trials (RCTs) that reported the primary outcome of change in hemoglobin $(\mathrm{Hb})$ level and iron utilization parameters, including ferritin, serum iron, TSAT, TIBC, transferrin, and hepcidin. Results: Ten RCTs were finally included with 3031 patients in the ROX group and 2737 patients in the control group. ROX was associated with increase in Hb level (SMD: 0.2; 95\% CI: 0.02, 0.39; P=0.03), TIBC (SMD: 0.79; 95\% CI: 0.61, 0.98; $\mathrm{P}<0.00001$ ), serum iron (SMD: 0.27; 95\% CI: 0.18, 0.36; $<<0.00001$ ), transferrin (SMD: 0.98; 95\% CI: 0.81, 1.15; P<0.00001) and decrease in hepcidin (SMD: $-15.53 ; 95 \%$ CI: -28.07, -3.00; $\mathrm{P}<0.02$ ) when compared with control group. There was no difference between ROX and the control group regarding ferritin level and TSAT. Sensitivity analysis by removing the most recent studies, Chen et al. or Hou et al. did not show significant difference in regard to change in Hb level. There was no difference between both groups regarding the serious side effects. However, ROX showed higher TEAEs when compared to the control group (RR: $1.03 ; 95 \% \mathrm{CI}: 1.01,1.05 ; \mathrm{P}=0.002$ ).
\end{abstract}

^ ORCID: Basel Abdelazeem, 0000-0002-2919-6196; Kirellos Said Abbas, 0000-0003-0339-9339; Joseph Shehata, 0000-0002-3373-7047; Nahla Ahmed El-Shahat, 0000-0002-6756-1764; Pramod Savarapu, 0000-0001-6614-2229. 
Discussion: Our updated meta-analysis concluded that ROX increased Hb level and improved iron utilization parameters in DD-CKD patients, but ROX was associated with higher TEAEs. Our results support the use of ROX for DD-CKD patients with anemia. However, higher-quality RCTs are still needed to confirm the results of our review.

Keywords: Roxadustat; anemia; dialysis; chronic kidney disease; iron

Submitted Aug 25, 2021. Accepted for publication Oct 22, 2021.

doi: 10.21037/atm-21-4357

View this article at: https://dx.doi.org/10.21037/atm-21-4357

\section{Introduction}

Chronic kidney disease (CKD) is defined as kidney damage or diminished renal function for three months or more, regardless of cause (1). The worldwide prevalence of CKD is $13 \%$ (2), and over 2 million CKD people worldwide currently receive treatment with dialysis (3). However, $\mathrm{CKD}$ is associated with increased morbidity and mortality rate; the mortality risk among those requiring dialysis is the highest within the first year after starting dialysis (4). One of the most common complications of CKD is anemia, with $14.0 \%$ of CKD patients had anemia in the United States of America between 2007-2010 (5).

The pathogenesis of CKD-related anemia is multifactorial, including but not limited to erythropoietin (EPO) deficiency, EPO inhibition by the uremia, and disruption of the iron homeostasis (6). The standard of care of anemia in Dialysis dependent CKD (DD-CKD) patients is iron replacement, erythropoietin stimulating agents (ESA), and blood transfusion. Before starting the patients on ESA therapy, the adverse effects of ESA should be explained to the patients before starting the treatment. ESA's side effects include serious cardiovascular events, myocardial infarction (MI), stroke, and venous thromboembolism (7-9). In addition, ESA is given subcutaneously, and iron therapy requires a hospital or infusion center visit to deliver the intravenous (IV) iron. And both of those factors can affect patients' compliance.

Recently, a new medication called roxadustat (ROX) had been released to the market to treat anemia in patients with DD-CKD. ROX is an oral medication that inhibits the hypoxia-inducible factor prolyl hydroxylase (HIF-PH) enzyme. Hypoxia-inducible factor (HIF) is an important transcription factor that regulates the oxygen response at the tissue level and induces erythropoiesis. HIF-PH is an enzyme that inhibits the activity of HIF, and inhibiting HIF-PH will lead to an increase in the level of HIF, which in return will increase EPO production $(10,11)$. ROX binds to plasma protein, mainly albumin, and the fraction unbound is about $1.2 \%$ in DD-CKD (12). ROX is mainly removed from the body by phase I oxidation (CYP2C8) and phase II conjugation (glucuronidation and glucosidation); thus, dialysis accounts for a small portion of the ROX elimination $(12,13)$. Few RCTs studied the effect of ROX compared to ESA on DD-CKD patients, but there were conflicting results regarding the efficacy and safety of ROX on DD-CKP patients.

Our updated meta-analysis of randomized clinical trials (RCTs) will include the recently published RCTs by Provenzano et al. (14), Hou et al. (15), and Charytan et al. (16). We aim to investigate the safety and efficacy of ROX versus ESA on DD-CKD patients with anemia. In addition, our study will provide evidence to the internists and nephrologists on whether ROX should be considered in clinical practice. We present the following article in accordance with the PRIMSA reporting checklist (available at https://dx.doi.org/10.21037/atm-21-4357).

\section{Methods}

This systematic review was registered with and was written and reported according to the guidelines of the Preferred Reporting for Systematic Review and Meta-Analysis (PRISMA) and Cochrane Handbook for Systematic Reviews of Interventions $(17,18)$. We registered our review at OSF Registries with DOI: 10.17605/OSF.IO/MJRA2.

\section{Data sources and search strategy}

Systematic and comprehensive research was conducted on the online databases PubMed, EMBASE, Scopus, Web of Science, Cochrane Central, and Google Scholar. It was carried out from inception up to July 2021 to include 
citations on HD CKD patients treated with ROX for anemia. A combination of the medical search terms and keywords were used to identify the potential articles of interest: (Roxadustat OR ASP1517 OR FG4592 OR "FG4592”) AND (kidney OR renal) AND (Anemia), and it varies depends on the database Table S1. We also used the related articles feature (19) to include any related articles and manually retrieved the bibliographies of relevant publications to avoid missing potential studies. Finally, we used EndNote (20) to save the search result. The search strategy was developed by (KSA and JS) and was peerreviewed by BA.

\section{Study selection and eligibility criteria}

Studies included in this systematic review were RCTs that were in English and met the following criteria: (I) Types of participants: participant were patients diagnosed with CKD and on dialysis; (II) Types of interventions: interventions used ROX to treat anemia; (III) Types of comparators: comparators were ESA or placebo; (IV) Types of outcomes: primary outcomes: change in hemoglobin level and iron utilization parameters.

Studies were excluded if they were observational, nonrandomized, or did not report a comparator group. Two independent reviewers (JS and KSA) used Covidence software (21) and screened the studies in three stages: title, abstract, and full text. BA resolved discrepancies between the reviewers.

\section{Data extraction}

Three reviewers (JS, KSA, and NA) independently extracted data from the included studies using Microsoft Excel. Any disagreements or discrepancies were resolved through discussion. Each included RCT was abstracted for the first author, published date, country, study design, phase, study period, study period, number of patients, age, gender, ROX dose.

\section{Risk of bias assessment}

The risk of bias was assessed independently by two Reviewers (KS and NA) using The Cochrane Collaboration's tool for assessing the risk of bias in randomized trials (22). The following items were evaluated: (I) Random sequence generation; (II) Allocation concealment; (III) Blinding of participants and personnel; (IV) Blinding of outcome assessment; (V) Incomplete outcome data; (VI) and Selective reporting. The trial was judged to be a low, unclear, or high risk of bias.

\section{Outcomes of interest}

The primary outcomes are changes in hemoglobin $(\mathrm{Hb})$ level and iron utilization parameters, including ferritin, serum iron, TSAT, TIBC, transferrin, hepcidin, and $\mathrm{Hb}$ in reticulocytes. Secondary outcomes are treatment-emergent adverse effects (TEAEs) and serious adverse events.

\section{Statistical analysis}

We reported the outcomes of interest in risk ratios (RRs) for dichotomous outcomes and the standardized mean difference (SMD) for the continuous outcomes using the Mantel-Haenszel method, and both presented it along with the corresponding $95 \%$ confidence interval (CI). Heterogeneity was estimated using the Cochran Q test and measured using I 2 statistics. The fixed-effects model was used in case of low heterogeneity $(\mathrm{P}<0.10$ and $\left.\mathrm{I}^{2}<50 \%\right)$, whereas the random-effects model in case of high heterogeneity ( $\mathrm{P} \geq 0.10$ and $\left.\mathrm{I}^{2} \geq 50 \%\right)$ (23). We conducted a sensitivity analysis in which one study was excluded at a time to assess the impact of each study on the overall pooled effects on the $\mathrm{Hg}$ level

Egger regression test was used to assess publication bias (24) using the Comprehensive Meta-analysis program (CMA) (25). Subgroup analyses were carried out using the trial phase to identify potential moderators and their effect on the $\mathrm{Hb}$ level. Two authors (KSA and NA) performed the meta-analysis using RevMan manager v5.3 (26), and the results were reviewed by (BA and JS).

\section{Results}

\section{Search results and study selection}

As shown in the PRISMA flow diagram Figure 1, a total of 908 articles were identified from our literature search, with one more identified through other sources. Once we applied the inclusion and exclusion criteria, a total of 64 studies were chosen for full full-text review. Finally, we included ten RCTs in our systematic review and meta-analysis (14-16,27-33). 


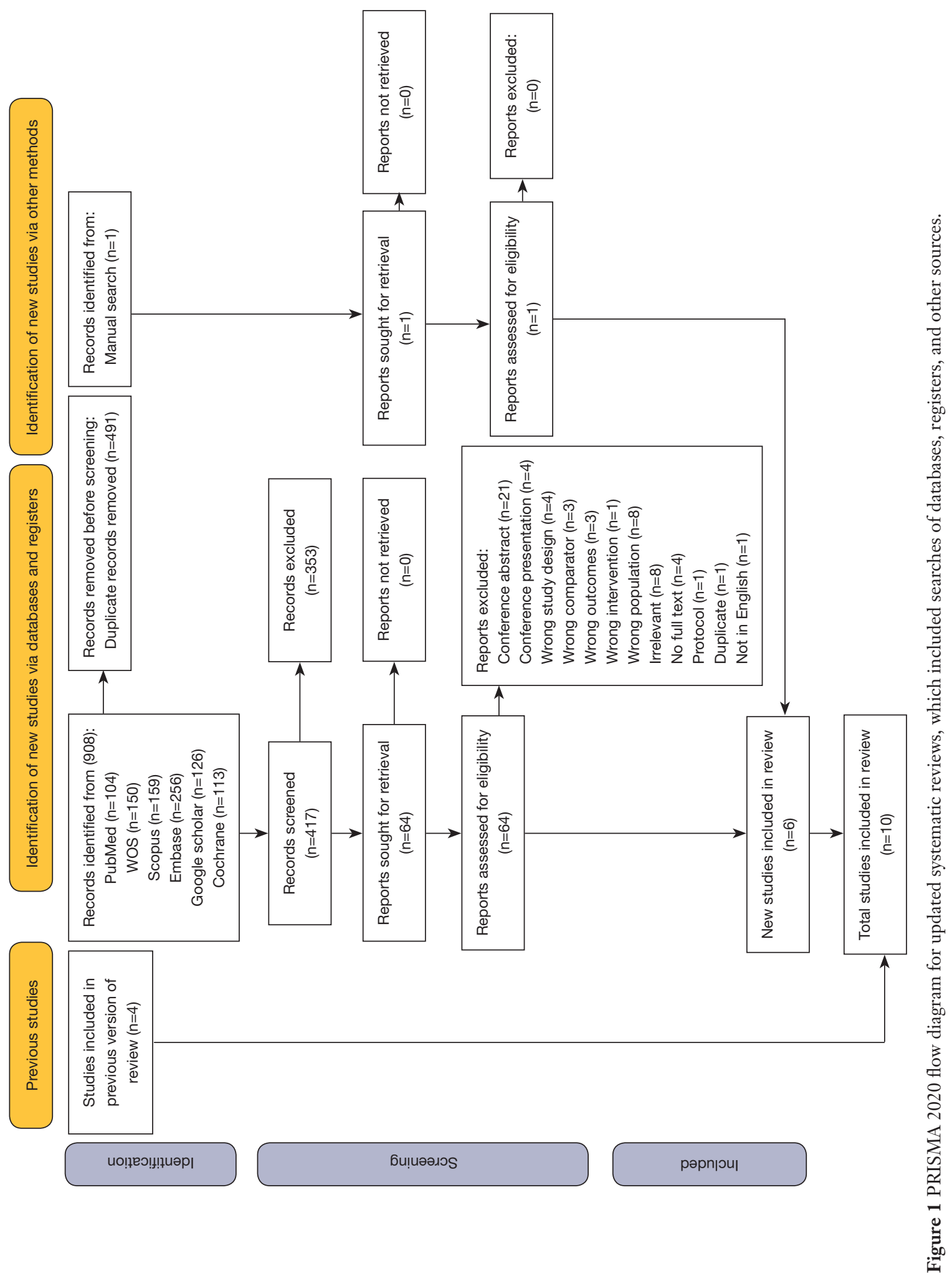




\section{Characteristics of included studies}

Detailed characteristics of the individual studies and the patients' demographics are summarized in Table 1. Three studies in China $(15,32,33)$, three studies in the United States of America $(14,16,30)$, two studies in Japan $(27,31)$, and two studies were global $(28,29)$. One RCTs were doubleblinded (31), and the rest were open-label. A total of six RCTs were phase $3(14,16,28,29,31,32)$, three were phase 2 $(27,30,33)$, and one was phase 4 (15). A total of 5768 patients were included, with 3031 patients in the ROX group compared to 2737 patients in the control group. All studies compared ROX to ESA. ROX doses range from $50 \mathrm{mg}$ to $200 \mathrm{mg}$ three times a week, and two studies use doses ranging from 1.0 to $2.3 \mathrm{mg} / \mathrm{kg}$ depending on body weight $(30,33)$. The duration of the included studies ranged from 6 weeks up to 4 years. The average age of the included patients was 55 years, and $62 \%$ were male. In the ROX group, the $\mathrm{Hg}$ ranged from 8.4 to $11 \mathrm{~g} / \mathrm{dL}$, TSAT\% ranged from $27 \%$ to $43 \%$, ferritin ranged from 190.2 to $1,002.02 \mathrm{ng} / \mathrm{mL}$, and finally, hepcidin ranged from 142.8 to $327.1 \mathrm{ng} / \mathrm{mL}$. The baseline laboratory values of the included patients are summarized in Table S2. Five RCTs reported the role of ROX in the inflammatory process, and they assessed the C-reactive protein (CRP) as a factor (14-16,31,32). The patients were divided into two groups according to the upper limit of normal (ULN) for CRP. The ULN was 3 in $(15,31)$ and 4.9 in (32). The CRP for most of the included patients was less than the ULN, and CRP was less in the ROX than the control group (Table S3).

\section{Risk of bias of the included studies and publication bias}

Figure 2 displayed a summary of the risk of bias assessment. Only Randomized control trials were included in this review. The risk of performance bias and detection bias was low in one RCTs (31), and the rest of the included RCTs were at a high risk of bias. Random sequence generation was low risk in seven RCTs $(14-16,27,28,31)$ and unclear risk of bias in four RCTs $(29,30,32,33)$. Allocation concealment was a low risk of bias in four RCTs $(14,16,31,32)$, and six RCTs were unclear risk of bias (15,27-30,33). Attrition bias was low risk for all included RCTs, except one was high risk (14). Finally, the reporting bias was low risk for most of the included RCTs, except one had a high risk of bias, and one had an unclear risk of bias (16). Using Egg's test, no evidence of publication bias was found in any of the outcomes (Table S4).

\section{Primary endpoints}

\section{Hemoglobin level}

There was an increase in the $\mathrm{Hb}$ level in the ROX group when compared to the control group (SMD: 0.21; 95\% CI: 0.02, 0.39; $\mathrm{P}=0.03$ ) (Figure 3, Forest plot A). We performed sensitivity analysis by omitting one study at time. We found that were no difference between the ROX and control groups when we excluded Chen et al. (33) or Hou et al. (15), (SMD: 0.18; 95\% CI: -0.01, 0.37; P=0.06), (SMD: 0.10; 95\% CI: -0.04, 0.24; $\mathrm{P}=0.16$ ), respectively (Table S5). This outcome was further subgrouped based on the RCTs trial phase 2 or 3 , and no significant difference was found between the ROX and control group. Three RCTs were in phase two (SMD: 0.19; 95\% CI: -0.18 , $0.57 ; \mathrm{P}=0.31)(27,30,33)$ and six RCTs were in phase three (SMD: $0.08 ; 95 \% \mathrm{CI}:-0.07,0.24 ; \mathrm{P}=0.31$ ) $(14,28,29,31,32)$ (Figure S1).

\section{Iron parameters}

When compared to the control group, ROX showed decrease in hepcidin (SMD: -15.53 ; 95\% CI: $-28.07,-3.00$; $\mathrm{P}<0.02$ ) (Figure 3, Forest plot B). And ROX showed increase in TIBC (SMD: 0.79; 95\% CI: 0.61, 0.98; $\mathrm{P}<0.00001$ ) (Figure 3, Forest plot C), serum iron (SMD: 0.27; 95\% CI: 0.18, 0.36; $\mathrm{P}<0.00001$ ) (Figure 3, Forest plot D), transferrin (SMD: 0.98; 95\% CI: 0.81, 1.15; $\mathrm{P}<0.00001)$ (Figure 3, Forest plot E). There was no difference between ROX and control group regarding ferritin level (SMD: -0.08 ; 95\% CI: $-0.21,0.05$; $\mathrm{P}=0.20$ ) (Figure 3, Forest plot F), TSAT (SMD: 0.04; $95 \%$ CI: -0.04, 0.11; P=0. 33) (Figure 3, Forest plot $\mathrm{G}$ ).

\section{Secondary endpoints}

Neither group showed any difference regarding the serious side effects (RR: 1.04; 95\% CI: 0.99, 1.10; $\mathrm{P}=0.11$ ) (Figure 4, Forest plot A). However, the ROX group showed higher TEAEs when compared to the control group (RR: 1.03; 95\% CI: 1.01, 1.05; $\mathrm{P}=0.002$ ) (Figure 4, Forest plot B).

The ROX group showed more gastrointestinal adverse effects compared to the control group (RR: 1.40 ; 95\% CI: 1.04, 1.88; $\mathrm{P}=0.03$ ) (Figure 4, Forest plot C). However, there was no difference between both groups regarding cardiovascular adverse effects; injury, poisoning, and procedural complications; muscle spasm; infection or infestation; upper respiratory tract infections; hypertension; and hyperkalemia (Figures S2-S8). 


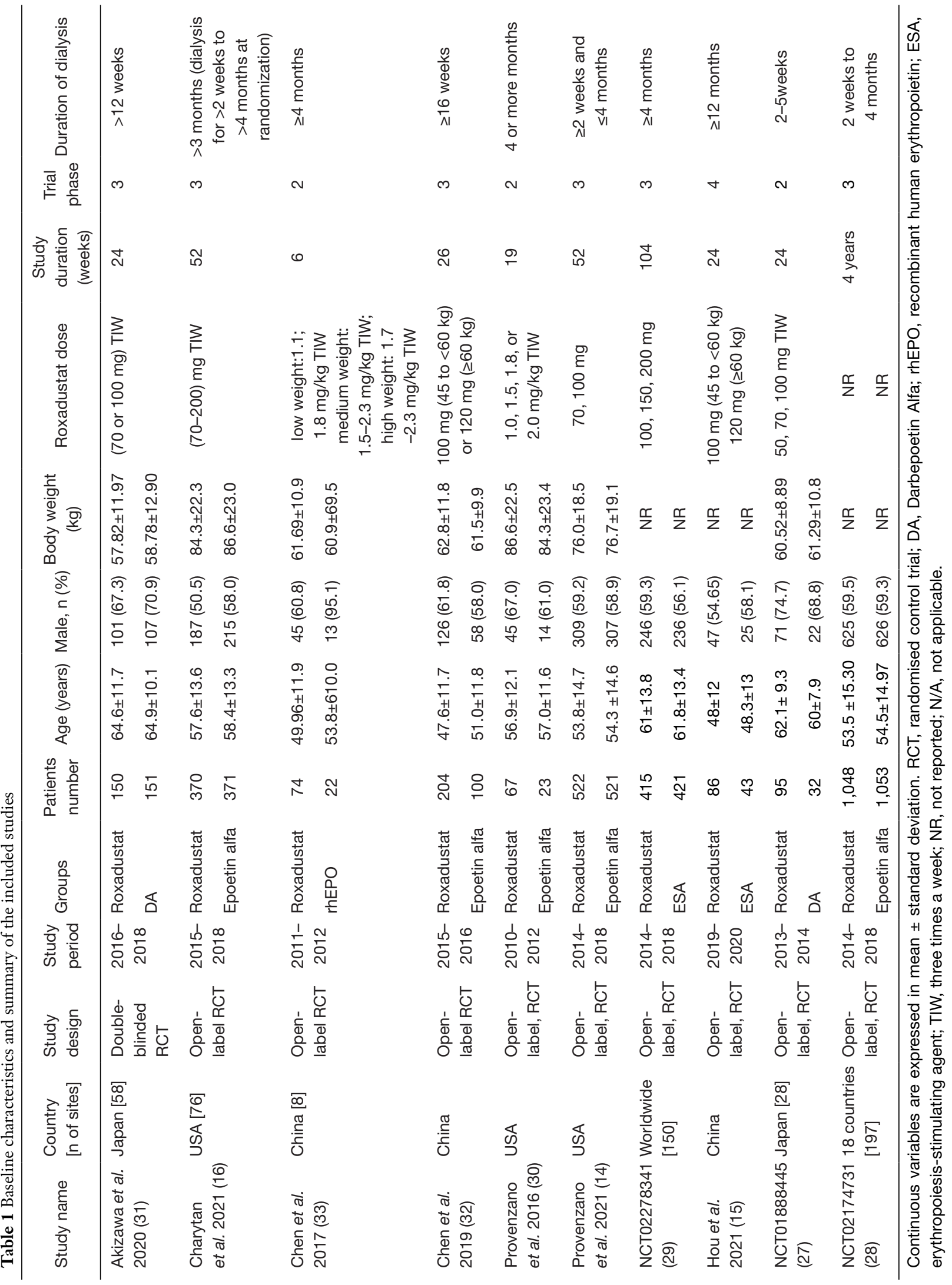




\section{Discussion}

Ten RCTs were included in our updated meta-analysis to evaluate the safety and efficacy of ROX compared to ESA in DD-CKD patients with anemia. We concluded that ROX increases $\mathrm{Hb}$ level, but when we excluded Chen et al. (33) or Hou et al. (15), no difference between both groups was noted. DD-CKD patients will need higher doses of ESA to treat anemia, likely secondary to the effect of inflammation on ESA (34). Inflammation can increase hepcidin and impair erythropoiesis $(35,36)$. So higher doses of ESA were used in the included RCTs, which can contribute to comparable effects in both groups. Another factor to be considered is the time of initiating dialysis and the ROX. Provenzano et al. and Charytan et al. conducted their study on patients on DD-CKS who started dialysis for more than two weeks and less than four months. They concluded that ROX increased Hb level by (mean \pm SD) $2.57 \pm 1.27$ and $0.39 \pm 0.93$ compared to $2.36 \pm 1.21$ and $-0.09 \pm 0.84$ in the epoetin alfa (EA) group $(14,16)$, respectively. In addition, Chen et al. include patients who started dialysis for at least 16 weeks, and they found that ROX increased hemoglobin level by $0.7 \pm 1.1$ compared to $0.5 \pm 1$ in the EA group (32).

We also observed that ROX improved iron parameters by decreasing hepcidin and increasing TIBC, serum iron, and transferrin. There was no difference noted between the two groups regarding ferritin and TSAT. This effect contributed to the mobilization of iron stores by ROX. $\mathrm{ROX}$ acts as an iron sensor and regulator by stimulating the genes involved in iron metabolism, leading to a decrease in hepcidin and an increase in cellular transferrin uptake and transferrin receptor, which increase iron absorption from the intestine. Also, ROX will promote heme-oxygenase-1 and ferroportin, which will help in iron oxidation and recycling of iron, respectively (10). Hepcidin is described by Ruchala et al. to be "iron gatekeeper or ferrostat" due to its regulatory action on iron reflux (37). Hepcidin works on iron sequestration in macrophage and hepatocytes, limiting its absorption in the intestine.

Moreover, hepcidin downregulates ferroportin preventing iron reflux (38). Erythropoietic stimulators negatively regulate hepcidin (39). Newly discovered drugs like ROX bind to HIF-prolyl hydroxylase enzymes, inhibiting their action with subsequent increase in HIF concentration. HIF increases expression of erythropoietin, works on a 3' enhancer of the erythropoietin gene, reduces hepcidin, and regulates genes responsible for iron metabolism $(40,41)$.
Our results also showed that ROX had higher TEAEs when compared to the ESA. Still, there was no difference between both groups regarding the serious side effects indicating similar safety concerns between both groups. Hyperkalemia is one of the TEAEs, and studies showed different incidences. Charytan et al. reported an almost similar percentage of hyperkalemia between the ROX group, $16.2 \%$, compared with $15.1 \%$ in the EA group (16). Some studies showed a low incidence of hyperkalemia in the ROX group compared with EA (5\% vs. 7\%) (14). However, other studies showed higher incidence in the ROX group, such as Hou et al., who reported 9\% in the ROX group and $5 \%$ in the ESA group suffered from hyperkalemia (15). In our meta-analysis, there was no difference between ROX and the control group regarding hyperkalemia.

Gastrointestinal disorder is a common adverse event, and it occurs at a higher rate in the ROX group $(14,15,31,32)$. And our results confirmed that the ROX group had higher gastrointestinal adverse effects compared to the control group. In Charytan et al., a higher rate of diarrhea and constipation in the EA group were observed (16), and in NCT01888445 higher incidence in gastrointestinal disorders were reported in the darbepoetin alfa group (27). Upper respiratory tract infection and nasopharyngitis are common TEAEs and usually occurred in the ROX group more frequently than in the control group (14-16). In addition, hypertension occurred more frequently in the ROX group than in the EA group $(14,16)$; while, it was also reported to occur in a lower incidence in the ROX group $(15,32,33)$.

ESA therapy is associated with an increased risk of cardiovascular adverse events $(9,42)$. Our results showed no significant difference between ROX and the control group regarding cardiovascular adverse events. However, few of the included studies were not powered to detect the cardiovascular adverse effects like Akizawa et al. In other RCTs, the included patients with any cardiovascular events in the past were excluded (33). However, Provenzano et al. 2016, reported three deaths for patients who had significant cardiovascular risks, but none of the deaths was attributed to ROX. Clearly, further research will be needed to validate the cardiovascular effects of ROX.

However, ROX was well tolerated, and the patients were more compliant with it due to the oral route of the medication compared to the subcutaneous route in the ESA. In addition, iron supplementation is associated with iron overload and hypersensitivity reaction, which ROX can avoid (35). 
A

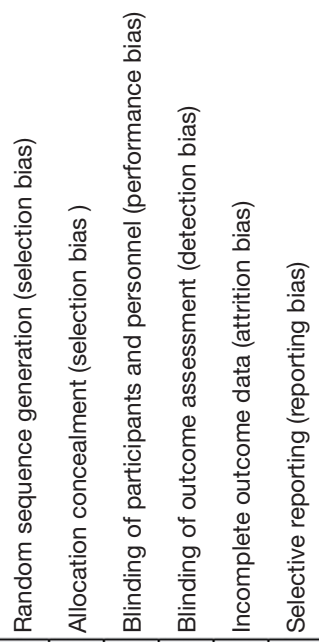

\begin{tabular}{|c|c|c|c|c|c|c|}
\hline Akizawa et al. 2020 & + & + & + & + & + & + \\
\hline Charytan et al. 2021 & + & + & $\theta$ & $\theta$ & + & $?$ \\
\hline Chen et al. 2017 & $?$ & $?$ & $\theta$ & $\theta$ & + & + \\
\hline Chen et al. 2019 & $?$ & + & 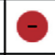 & $\odot$ & + & + \\
\hline Hou et al. 2021 & + & $?$ & $\theta$ & $\odot$ & + & + \\
\hline NCTO1888445 2018 & + & $?$ & $\theta$ & $\Theta$ & $\odot$ & + \\
\hline NCT02174731 2020 & + & $?$ & $\theta$ & 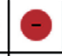 & $\odot$ & + \\
\hline NCT02278341 2019 & $?$ & $?$ & $\theta$ & 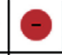 & + & + \\
\hline Provenzano et al. 2016 & $?$ & $?$ & - & $\theta$ & 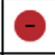 & O \\
\hline Provenzano et al. 2021 & + & + & $\theta$ & $\theta$ & + & + \\
\hline
\end{tabular}

B Random sequence generation (selection bias) Allocation concealment (selection bias Blinding of participants and personnel (performance bias) Blinding of outcome assessment (detection bias) Incomplete outcome data (attrition bias) Selective reporting (reporting bias)

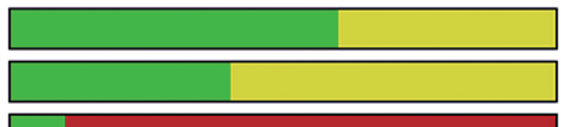

L

$$
\text { s) } \square
$$

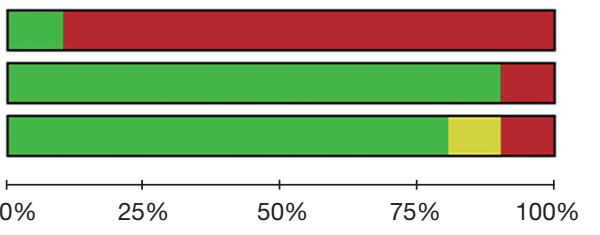

Low risk of bias Unclear risk of bias High risk of bias

Figure 2 Risk of bias assessment. (A) Risk of bias summary: review authors' judgments about each risk of bias item for each included study. The items are scored (+) low risk; (-) high risk; (?) unclear risk of bias. (B) Risk of bias graph: review authors' judgments about each risk of bias item presented as percentages across all included studies. 
A Forest plot of comparison: 1 Primary Outcomes, outcome: 1.1 Hemoglobin.

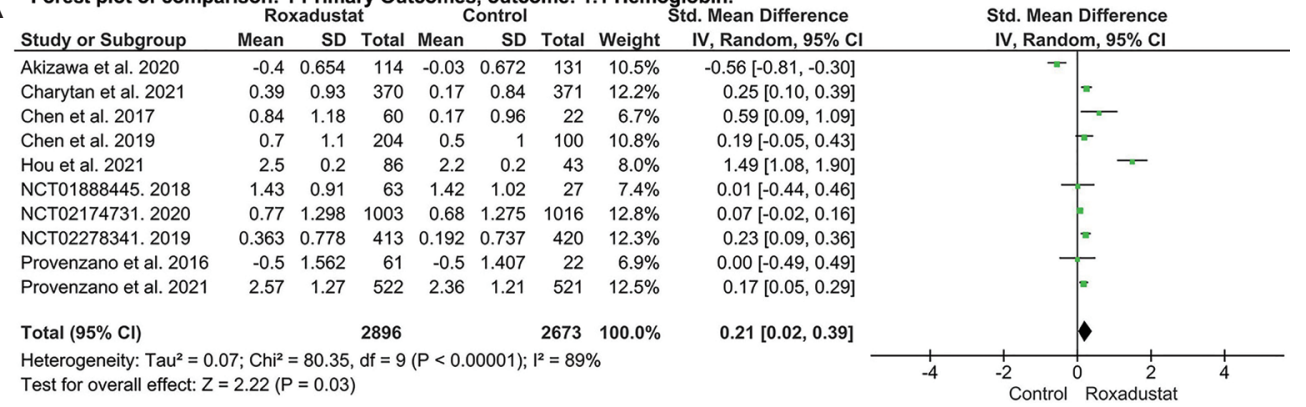

B Forest plot of comparison: 1 Primary Outcomes, outcome: 1.2 Hepcidin

B Forest plot of comparison: 1 Primary Outcomes, outcome: 1.2 Hepcidin. $\begin{array}{lllllll}\text { Study or Subgroup } & \text { Mean SD Total } & \text { Mean } & \text { SD Total Weight } & \text { Mean Difference } & \text { IV, Random, } 95 \% \mathrm{Cl} & \text { Mean Difference } \\ \text { IV, Random, } 95 \% \mathrm{C}\end{array}$ \begin{tabular}{llllrrrrr}
\hline Akizawa et al. 2020 & 2.308 & 27.279 & 150 & -0.6 & 27.061 & 151 & $23.1 \%$ & $2.91[-3.23,9.05]$
\end{tabular} $\begin{array}{lllllllll}\text { Charytan et al. } 2021 & -95.53 & 148.27 & 230 & -66.66 & 141.61 & 265 & 12.1 \% & -28.87\end{array}[-54.52,-3.22]$ $\begin{array}{llrrrrrrr}\text { Chen et al. } 2017 & -70.2 & 104.19 & 60 & -77.9 & 75.18 & 22 & 6.8 \% & 7.70[-33.31,48.71]\end{array}$ \begin{tabular}{lllllllll} 
Chen et al. 2019 & -30.2 & 113.3 & 155 & -2.3 & 130.7 & 90 & $9.3 \%$ & -27.90 \\
\hline
\end{tabular} $\begin{array}{lllllllll}\text { Hou et al. } 2021 & -46.6 & 79.7 & 57 & -5.9 & 87.6 & 29 & 7.5 \% & -40.70[-78.71,-2.69]\end{array}$ $\begin{array}{lllllllll}\text { NCT02278341. } 2019 & -32.709 & 42.342 & 310 & -17.522 & 47.307 & 357 & 22.8 \% & -15.19[-21.99,-8.38\end{array}$ $\begin{array}{lrrrrrrrr}\text { Provenzano et al. } 2016 & -60.4 & 187.8 & 46 & 35.6 & 123.4 & 18 & 2.3 \% & -96.00[-174.71,-17.29]\end{array}$

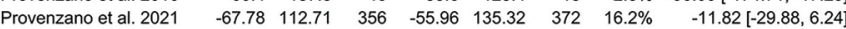
Total $(95 \% \mathrm{Cl}) \quad 1364 \quad 1304 \quad 100.0 \% \quad-15.53[-28.07,-3.00]$ Heterogeneity: $\mathrm{Tau}^{2}=167.55 ; \mathrm{Chi}^{2}=28.65, \mathrm{df}=7(\mathrm{P}=0.0002) ; \mathrm{I}^{2}=76 \%$ Test for overall effect: $Z=2.43(P=0.02)$

Corest plot of comparison: 1 Primary Outcomes, outcome: 1.3 TIBC. \begin{tabular}{ccccccc} 
Roxadustat & \multicolumn{2}{c}{ Control } & Std. Mean Difference & Std. Mean Difference \\
Study or Subgroup & Mean & SD Total & Mean & SD Total Weight & IV, Random, $95 \% \mathrm{Cl}$ & IV, Random, $95 \% \mathrm{Cl}$
\end{tabular} $\begin{array}{lllllllll}\text { Akizawa et al. } 2020 & 7.8 & 8.1 & 150 & 1.6 & 5.7 & 151 & 16.8 \% & 0.88[0.65,1.12]\end{array}$ $\begin{array}{lllllllll}\text { Charytan et al. } 2021 & 252.09 & 50.04 & 235 & 214.66 & 39.94 & 272 & 19.0 \% & 0.83[0.65,1.01]\end{array}$

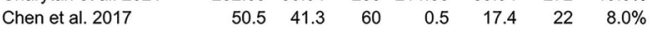
$\begin{array}{llllllll}\text { Chen et al. } 2019 & 10 & 11.9 & 159 & -1.1 & 9 & 93 & 15.5 \%\end{array}$ $\begin{array}{llllllll}\text { Hou et al. } 2021 & 7.1 & 15.7 & 78 & 2.6 & 24.4 & 39 & 11.6 \%\end{array}$ $\begin{array}{lllllllll}\text { Provenzano et al. } 2016 & 37.6 & 41.4 & 61 & 25.6 & 47.3 & 22 & 8.9 \%\end{array}$ $\begin{array}{lrrrrrrr}\text { Provenzano et al. 2016 } & 37.6 & 41.4 & 61 & 25.6 & 47.3 & 22 & 8.9 \% \\ \text { Provenzano et al. 2021 } & 37.7 & 43.1 & 364 & 1.65 & 43.641 & 383 & 20.2 \%\end{array}$

$\begin{array}{llll}\text { Total }(95 \% \mathrm{Cl}) \quad 1107 & 982 \quad \mathbf{1 0 0 . 0} \%\end{array}$ Heterogeneity: $\mathrm{Tau}^{2}=0.04 ; \mathrm{Chi}^{2}=19.71, \mathrm{df}=6(\mathrm{P}=0.003) ; \mathrm{I}^{2}=70 \%$ Test for overall effect: $Z=8.34(P<0.00001)$

$1.35[0.82,1.89]$ $1.01[0.74,1.28]$ $0.24[-0.15,0.62]$ $0.28[-0.21,0.77]$ $0.83[0.68,0.98]$ $0.79[0.61,0.98]$ Forest plot of comparison: 1 Primary Outcomes, outcome: 1.4 Serum Iron.

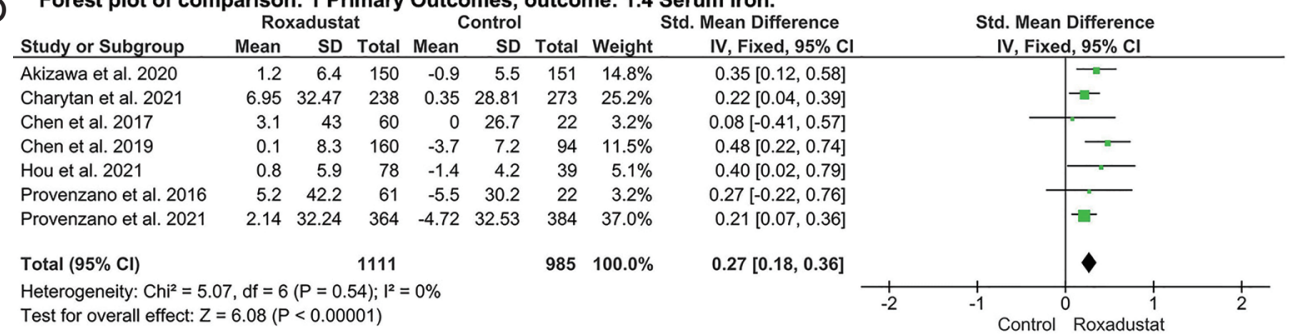

E Forest plot of comparison: 1 Primary Outcomes, outcome: 1.5 Transferrin.

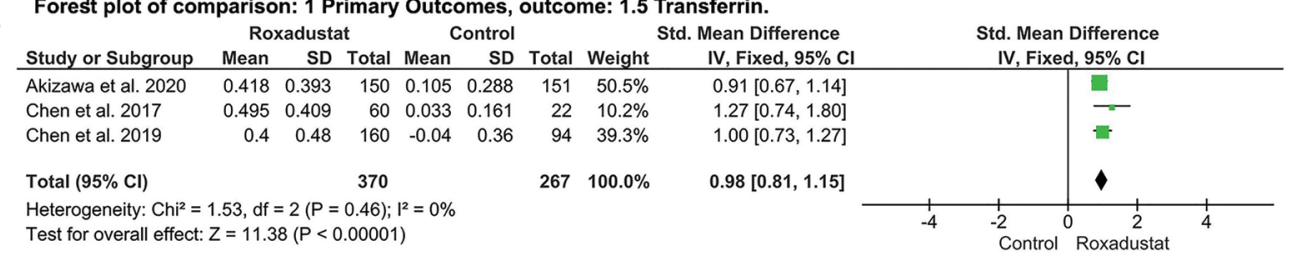

F Forest plot of comparison: 1 Primary Outcomes, outcome: 1.6 Ferritin.

\begin{tabular}{|c|c|c|c|c|c|c|c|c|c|c|c|}
\hline \multirow[b]{2}{*}{ Study or Subgroup } & \multicolumn{3}{|c|}{ Roxadustat } & \multicolumn{3}{|c|}{ Control } & \multicolumn{2}{|r|}{ Std. Mean Difference } & \multirow{2}{*}{\multicolumn{2}{|c|}{$\begin{array}{r}\text { Std. Mean Difference } \\
\text { IV, Random, } 95 \% \mathrm{CI}\end{array}$}} & \\
\hline & Mean & SD & Total & Mean & SD & Total & Weight & IV, Random, $95 \% \mathrm{CI}$ & & & \\
\hline Akizawa et al. 2020 & -3.98 & 78.41 & 150 & -18.75 & 64.64 & 151 & $14.1 \%$ & $0.21[-0.02,0.43]$ & & & \\
\hline Charytan et al. 2021 & -429.91 & 340.16 & 238 & -389.52 & 341.11 & 273 & $17.1 \%$ & $-0.12[-0.29,0.06]$ & $\rightarrow$ & & \\
\hline Chen et al. 2017 & -95 & 189 & 60 & -70 & 157 & 22 & $5.5 \%$ & $-0.14[-0.63,0.35]$ & & & \\
\hline Chen et al. 2019 & -119 & 208 & 160 & -136 & 220 & 94 & $12.6 \%$ & $0.08[-0.18,0.33]$ & & - & \\
\hline Hou et al. 2021 & -55.5 & 299.5 & 78 & -27.6 & 192.3 & 39 & $7.8 \%$ & $-0.10[-0.49,0.28]$ & & & \\
\hline NCT02278341. 2019 & -615.19 & 677.97 & 318 & -347.58 & $1,058.87$ & 365 & $18.5 \%$ & $-0.30[-0.45,-0.15]$ & - & & \\
\hline Provenzano et al. 2016 & -201.1 & 334.4 & 61 & -211.6 & 445.2 & 22 & $5.5 \%$ & $0.03[-0.46,0.52]$ & & & \\
\hline Provenzano et al. 2021 & -198.47 & 311.7 & 362 & -141.13 & 328.52 & 381 & $18.9 \%$ & $-0.18[-0.32,-0.03]$ & - & & \\
\hline Total $(95 \% \mathrm{Cl})$ & & & 1427 & & & 1347 & $100.0 \%$ & $-0.08[-0.21,0.05]$ & & & \\
\hline $\begin{array}{l}\text { Heterogeneity: } \operatorname{Tau}^{2}=0 \\
\text { Test for overall effect: } Z\end{array}$ & $\begin{array}{l}2 ; \mathrm{Chi}^{2}=1 \\
=1.27(\mathrm{P}=\end{array}$ & $\begin{array}{l}16.51, \mathrm{df} \\
=0.20)\end{array}$ & $7(\mathrm{P}$ & .02 & & & & -2 & $\begin{array}{ll}1 & 1 \\
-1 & 0\end{array}$ & Control & 1 \\
\hline
\end{tabular}




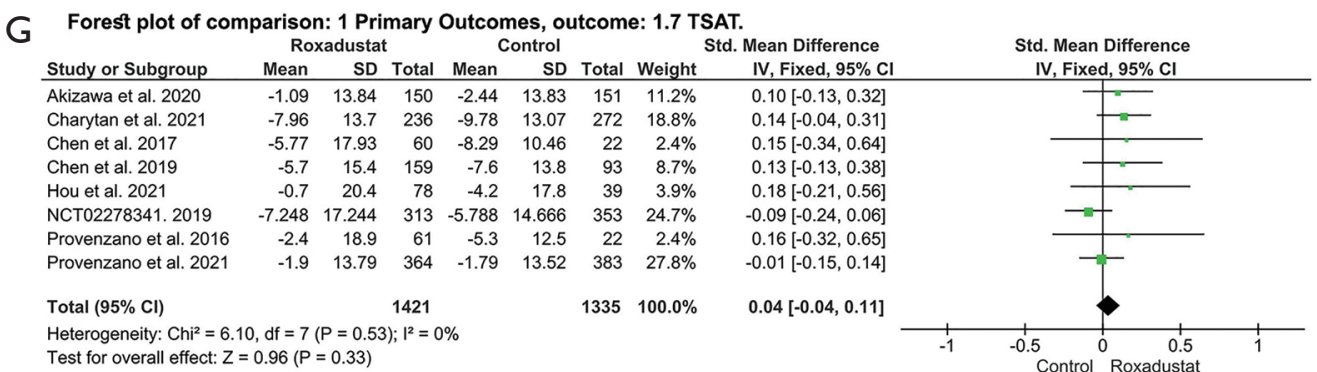

Figure 3 Forest plots of the primary outcomes. Hemoglobin $(\mathrm{g} / \mathrm{dL})$; hepcidin $(\mathrm{ng} / \mathrm{mL})$; TIBC $(\mu \mathrm{mol} / \mathrm{L})$; serum iron $(\mu \mathrm{mol} / \mathrm{L})$; transferrin $(\mathrm{g} / \mathrm{L})$; ferritin $(\mathrm{ng} / \mathrm{mL})$; TSAT $(\%)$. df, degrees of freedom; IV, inverse variance; CI, confidence interval.

A Forest plot of comparison: 2 Adverse effect, outcome: 2.1 Serious side effects.

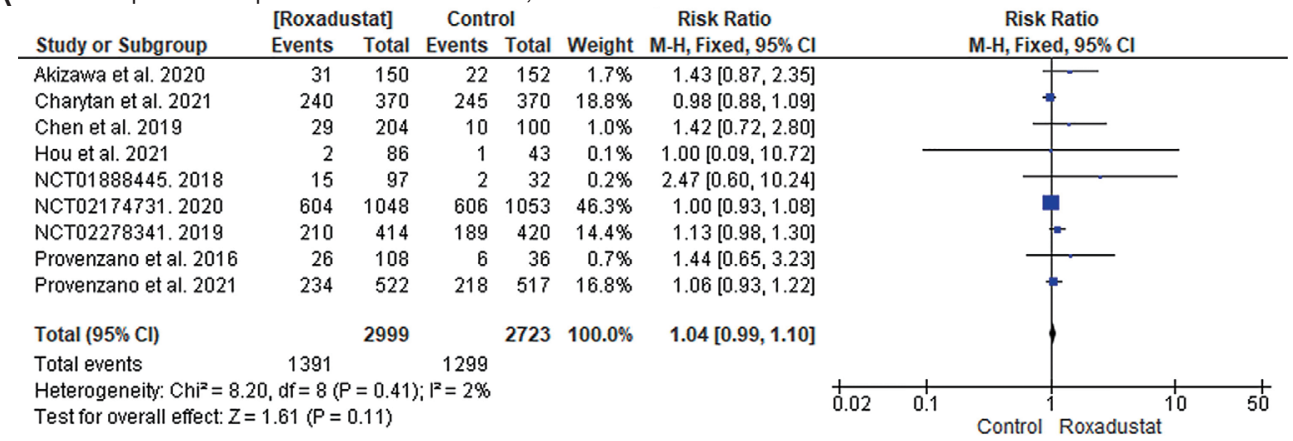

B Forest plot of comparison: 2 Adverse effect, outcome: 2.2 TEAEs.

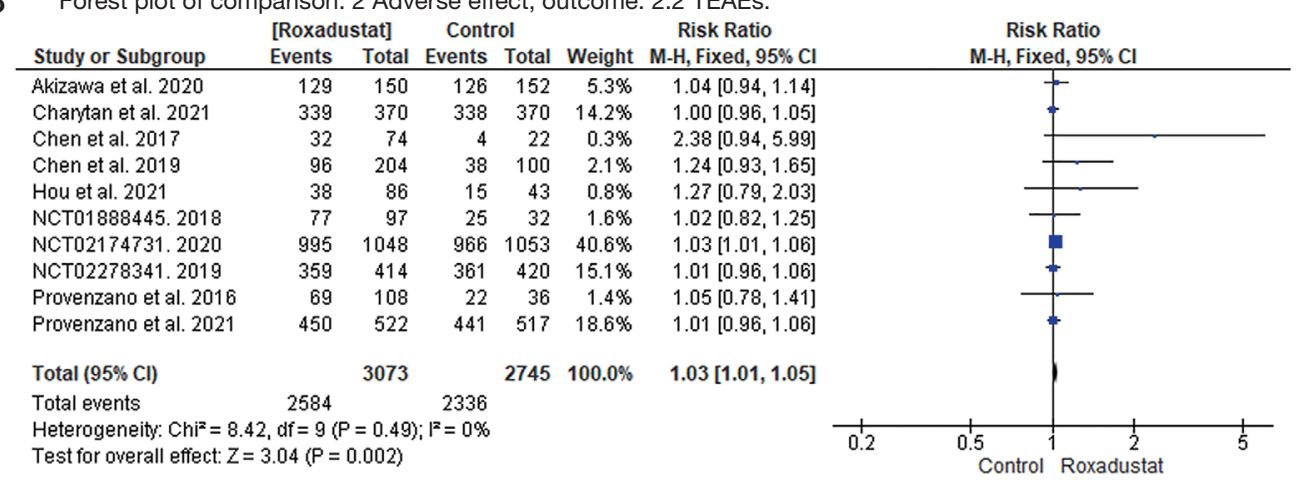

C Forest plot of comparison: 2 Adverse effect, outcome: 2.3 Gastrointestinal adverse effects.

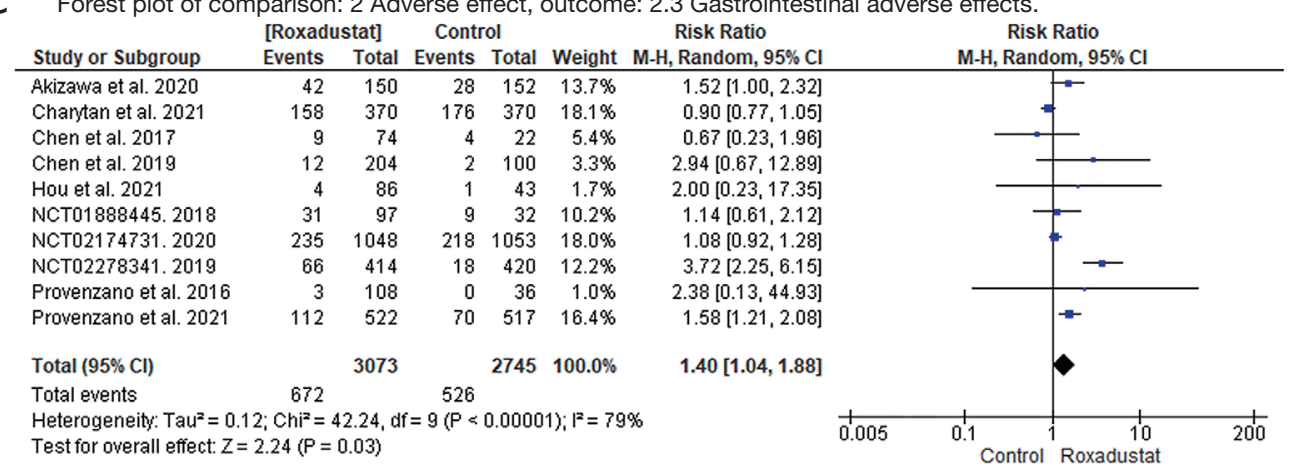

Figure 4 Forest plots of the secondary outcomes. TEAEs, treatment-emergent adverse effects; df, degrees of freedom; M-H, MantelHaenszel; CI, confidence interval. 
The previous meta-analysis of RCTs by Tang et al. (43) included seven RCTs with a total of 4,810 DD-CKD patients. They concluded that ROX was associated with increased hemoglobin level [weighted mean difference (WMD): 0.14; 95\% CI:0.05-0.23; $\mathrm{P}<0.001]$, transferrin level (WMD: 0.40; 95\% CI: 0.30-0.50; $\mathrm{P}<0.00001$ ), and TIBC level (WMD: 43.65; 95\% CI:33.78-53.53; $\mathrm{P}<0.00001$ ) and lowered the hepcidin level (WMD: $-11.49 \mathrm{ng} / \mathrm{mL} ; 95 \% \mathrm{CI}:-14.58,-8.41 ; \mathrm{P}<0.00001)$ and lowered the ferritin and TAST levels in DD-CKD patients. Also, they reported that there is no difference between the treatment-emergent adverse events (TEAEs) of ROX and ESAs or placebo except for serious TEAEs, which was higher in the ROX group (OR: 1.12; 95\% CI: 0.99-1.26; $\mathrm{P}<0.07)$. Tang et al. published their article before the release of Hou et al. (15), which limits their ability to assess and evaluate the article. They also used weighted mean difference during their meta-analysis; although different RCTs reported different measurement units and reference ranges, meanwhile we used standardized mean difference. We only did our meta-analysis on DD-CKD to focus on this patient's group, and we were able to do a detailed meta-analysis with all possible shared outcomes between the included RCTs and detailed sensitivity and subgroup analyses. We are currently conducting another updated systematic review and meta-analysis to assess the efficacy of ROX in treating anemia in non-dialysis-dependent CKD and was registered at OSF Registries with DOI 10.17605/ OSF.IO/WGZ6C.

\section{Strength and limitations}

To reduce the possibility of heterogeneity, we conducted our meta-analysis on DD-CKD patients. We comprehensively searched the literature and included 10 RCTs, one of which is a recent phase 4 trial (15) that had not previously been included in any systematic review and meta-analysis. As a result, we were able to assess publication bias using Egger's test, which many previous systematic reviews on the same topic could not do. The included RCTs spanned various ethnicities and geographical locations, allowing us to generalize the meta-analysis findings. However, our study has significant limitations. First, all of the trials included -except one (31) are open-label, which may increase performance bias. Second, different ROX dosages were used in the included RCTs, which may have resulted in some heterogeneity. Third, the majority of the included studies were financed by pharmaceutical manufacturers, which may have resulted in some bias. Finally, although the included studies reflect short-term findings, a long-term evaluation of the medication and its effect is also required. As a result, more high-quality, multinational, phase 3 and phase 4 studies with long-term evaluation and a large population are still required.

\section{Conclusions}

Our review included ten RCTs to assess the effect of ROX on DD-CKD patients with anemia. We conclude that ROX was associated with increased $\mathrm{Hb}$ level and improved iron utilization parameters by increasing TIBC, serum iron, transferrin, and decreasing hepcidin. In addition, ROX was associated with higher TEAEs and no difference between both groups regarding the serious side effects. However, higher-quality RCTs are still needed to confirm the results of our review.

\section{Acknowledgments}

Funding: None.

\section{Footnote}

Reporting Checklist: The authors have completed the PRISMA reporting Checklist. Available at https://dx.doi. org/10.21037/atm-21-4357

Peer Review File: Available at https://dx.doi.org/10.21037/ atm-21-4357

Conflicts of Interest: All authors have completed the ICMJE uniform disclosure form (available at https://dx.doi. org/10.21037/atm-21-4357). The authors have no conflicts of interest to declare.

Ethical Statement: The authors are accountable for all aspects of the work in ensuring that questions related to the accuracy or integrity of any part of the work are appropriately investigated and resolved. The informed consent was waived because this study was a meta-analysis of previously published RCTs and did not involve any processing of individual patient data.

Open Access Statement: This is an Open Access article distributed in accordance with the Creative Commons Attribution-NonCommercial-NoDerivs 4.0 International 


\section{Page 12 of 14}

License (CC BY-NC-ND 4.0), which permits the noncommercial replication and distribution of the article with the strict proviso that no changes or edits are made and the original work is properly cited (including links to both the formal publication through the relevant DOI and the license). See: https://creativecommons.org/licenses/by-nc-nd/4.0/.

\section{References}

1. KDIGO Clinical Practice Guideline for Anemia in Chronic Kidney Disease. 2012.

2. Simon JF, Nakhoul G. Correction: Anemia of chronic kidney disease. Cleve Clin J Med 2016;83:739.

3. Jha V, Garcia-Garcia G, Iseki K, et al. Chronic kidney disease: global dimension and perspectives. Lancet 2013;382:260-72.

4. Bradbury BD, Fissell RB, Albert JM, et al. Predictors of early mortality among incident US hemodialysis patients in the Dialysis Outcomes and Practice Patterns Study (DOPPS). Clin J Am Soc Nephrol 2007;2:89-99.

5. Stauffer ME, Fan T. Prevalence of anemia in chronic kidney disease in the United States. PLoS One 2014;9:e84943.

6. Babitt JL, Lin HY. Mechanisms of anemia in CKD. J Am Soc Nephrol 2012;23:1631-4.

7. Drüeke TB, Locatelli F, Clyne N, et al. Normalization of hemoglobin level in patients with chronic kidney disease and anemia. N Engl J Med 2006;355:2071-84.

8. Pfeffer MA, Burdmann EA, Chen CY, et al. A trial of darbepoetin alfa in type 2 diabetes and chronic kidney disease. N Engl J Med 2009;361:2019-32.

9. Singh AK, Szczech L, Tang KL, et al. Correction of anemia with epoetin alfa in chronic kidney disease. $\mathrm{N}$ Engl J Med 2006;355:2085-98.

10. Peyssonnaux $C$, Nizet $V$, Johnson RS. Role of the hypoxia inducible factors HIF in iron metabolism. Cell Cycle 2008;7:28-32.

11. Dhillon S. Roxadustat: First Global Approval. Drugs 2019;79:563-72.

12. Groenendaal-van de Meent D, Adel MD, Noukens J, et al. Effect of Moderate Hepatic Impairment on the Pharmacokinetics and Pharmacodynamics of Roxadustat, an Oral Hypoxia-Inducible Factor Prolyl Hydroxylase Inhibitor. Clin Drug Investig 2016;36:743-51.

13. Provenzano R, Tumlin J, Zabaneh R, et al. Oral HypoxiaInducible Factor Prolyl Hydroxylase Inhibitor Roxadustat (FG-4592) for Treatment of Anemia in Chronic Kidney Disease: A Placebo-Controlled Study of Pharmacokinetic

\section{Abdelazeem et al. Roxadustat for anemia in DD-CKD patients}

and Pharmacodynamic Profiles in Hemodialysis Patients. J Clin Pharmacol 2020;60:1432-40.

14. Provenzano R, Shutov E, Eremeeva L, et al. Roxadustat for anemia in patients with end-stage renal disease incident to dialysis. Nephrol Dial Transplant 2021;36:1717-30.

15. Hou YP, Mao XY, Wang C, et al. Roxadustat treatment for anemia in peritoneal dialysis patients: A randomized controlled trial. J Formos Med Assoc 2021. [Epub ahead of print].

16. Charytan C, Manllo-Karim R, Martin ER, et al. A Randomized Trial of Roxadustat in Anemia of Kidney Failure: SIERRAS Study. Kidney Int Rep 2021;6:1829-39.

17. Page MJ, McKenzie JE, Bossuyt PM, et al. The PRISMA 2020 statement: an updated guideline for reporting systematic reviews. Syst Rev 2021;10:89.

18. Page MJ, Moher D, Bossuyt PM, et al. PRISMA 2020 explanation and elaboration: updated guidance and exemplars for reporting systematic reviews. BMJ 2021;372:n160.

19. Sampson M, Shojania KG, McGowan J, et al. Surveillance search techniques identified the need to update systematic reviews. J Clin Epidemiol 2008;61:755-62.

20. The EndNote Team. EndNote. EndNote X9 ed. Philadelphia, PA: Clarivate; 2013.

21. Covidence systematic review software, Veritas Health Innovation, Melbourne, Australia. Available online: www. covidence.org.

22. Higgins JP, Altman DG, Gøtzsche PC, et al. The Cochrane Collaboration's tool for assessing risk of bias in randomised trials. BMJ 2011;343:d5928.

23. Higgins JP, Thompson SG. Quantifying heterogeneity in a meta-analysis. Stat Med 2002;21:1539-58.

24. Egger M, Davey Smith G, Schneider M, et al. Bias in meta-analysis detected by a simple, graphical test. BMJ 1997;315:629-34.

25. Borenstein M, Hedges, L., Higgins, J., \& Rothstein, H. Comprehensive Meta-Analysis Version 3. Biostat, Englewood, NJ 2013.

26. Review Manager (RevMan) [Computer program]. Version 5.3. Copenhagen: The Nordic Cochrane Centre, The Cochrane Collaboration, 2014.

27. NCT01888445. A Japanese, Phase 2, Multicenter, Randomized, 4-arm Parallel, Double-Blind (Arms 1-3), Open-Label (Arm 4), Active-Comparator (Darbepoetin Alfa) Study of Intermittent Oral Dosing of ASP1517 in Hemodialysis-dependent Chronic Kidney Disease Patients with Anemia. [Online]. Available online: https:// astellasclinicalstudyresults.com/hcp/study.aspx? (Accessed 
8/6/2021). 2018.

28. NCT02174731. A Phase 3, Multicenter, Randomized, Open-Label, Active Controlled Study of theSafety and Efficacy of Roxadustat in the Treatment of Anemia in Dialysis Patients. [Online]. Available online: https:// clinicaltrials.gov/ct2/show/NCT02174731. 2020.

29. NCT02278341. Roxadustat in the Treatment of Anemia in End Stage Renal Disease (ESRD) Patients on Stable Dialysis (Pyrenees) Available online: https://clinicaltrials. gov/ct2/show/results/NCT02278341. 2019.

30. Provenzano R, Besarab A, Wright S, et al. Roxadustat (FG-4592) Versus Epoetin Alfa for Anemia in Patients Receiving Maintenance Hemodialysis: A Phase 2, Randomized, 6- to 19-Week, Open-Label, ActiveComparator, Dose-Ranging, Safety and Exploratory Efficacy Study. Am J Kidney Dis 2016;67:912-24.

31. Akizawa T, Iwasaki M, Yamaguchi Y, et al. Phase 3, Randomized, Double-Blind, Active-Comparator (Darbepoetin Alfa) Study of Oral Roxadustat in CKD Patients with Anemia on Hemodialysis in Japan. J Am Soc Nephrol 2020;31:1628-39.

32. Chen N, Hao C, Liu BC, et al. Roxadustat Treatment for Anemia in Patients Undergoing Long-Term Dialysis. N Engl J Med 2019;381:1011-22.

33. Chen N, Qian J, Chen J, et al. Phase 2 studies of oral hypoxia-inducible factor prolyl hydroxylase inhibitor FG4592 for treatment of anemia in China. Nephrol Dial Transplant 2017;32:1373-86.

34. Saran R, Robinson B, Abbott KC, et al. US Renal Data System 2018 Annual Data Report: Epidemiology of Kidney Disease in the United States. Am J Kidney Dis

Cite this article as: Abdelazeem B, Abbas KS, Shehata J, El-Shahat NA, Baral N, Savarapu P, Kunadi A. The efficacy of Roxadustat for the treatment of anemia in dialysis dependent chronic kidney disease patients: an updated systematic review and meta-analysis of randomized clinical trials. Ann Transl Med 2021;9(23):1714. doi: 10.21037/atm-21-4357
2019;73:A7-8.

35. Macdougall IC, Bircher AJ, Eckardt KU, et al. Iron management in chronic kidney disease: conclusions from a "Kidney Disease: Improving Global Outcomes" (KDIGO) Controversies Conference. Kidney Int 2016;89:28-39.

36. Weiss G, Ganz T, Goodnough LT. Anemia of inflammation. Blood 2019;133:40-50.

37. Ruchala P, Nemeth E. The pathophysiology and pharmacology of hepcidin. Trends Pharmacol Sci 2014;35:155-61.

38. Malyszko J, Malyszko JS, Matuszkiewicz-Rowinska J. Hepcidin as a therapeutic target for anemia and inflammation associated with chronic kidney disease. Expert Opin Ther Targets 2019;23:407-21.

39. Donovan A, Lima CA, Pinkus JL, et al. The iron exporter ferroportin/Slc40a1 is essential for iron homeostasis. Cell Metab 2005;1:191-200.

40. Malyszko J, Malyszko JS. Emerging drugs for the treatment of kidney disease-induced anemia. Expert Opin Emerg Drugs 2016;21:315-30.

41. Muchnik E, Kaplan J. HIF prolyl hydroxylase inhibitors for anemia. Expert Opin Investig Drugs 2011;20:645-56.

42. Pfeffer MA, Burdmann EA, Chen CY, et al. Baseline characteristics in the Trial to Reduce Cardiovascular Events With Aranesp Therapy (TREAT). Am J Kidney Dis 2009;54:59-69.

43. Tang M, Zhu C, Yan T, et al. Safe and Effective Treatment for Anemic Patients With Chronic Kidney Disease: An Updated Systematic Review and Meta-Analysis on Roxadustat. Front Pharmacol 2021;12:658079. 


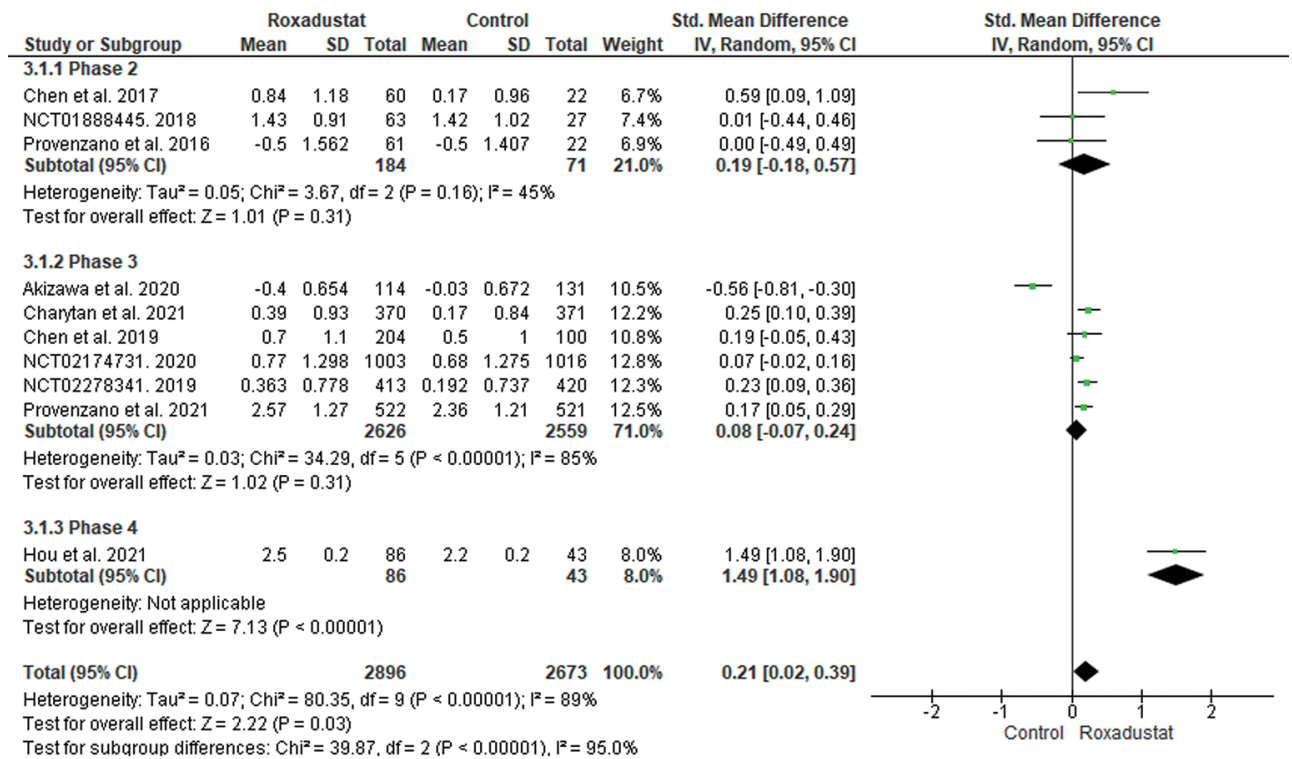

Figure S1 Forest plot of the Subgroup analysis.

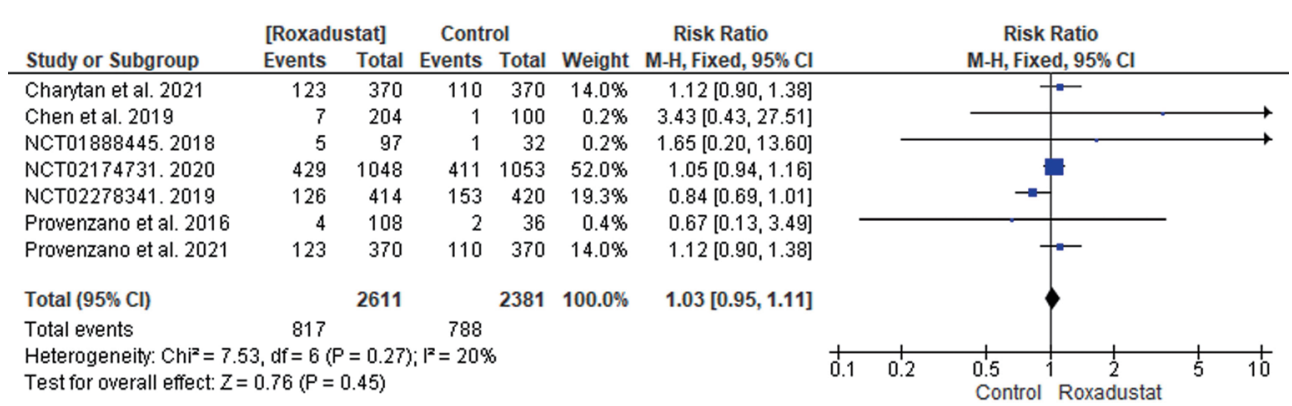

Figure S2 Forest plot of comparison: 2 Adverse effects, outcome: 2.4 Cardiovascular adverse effects.

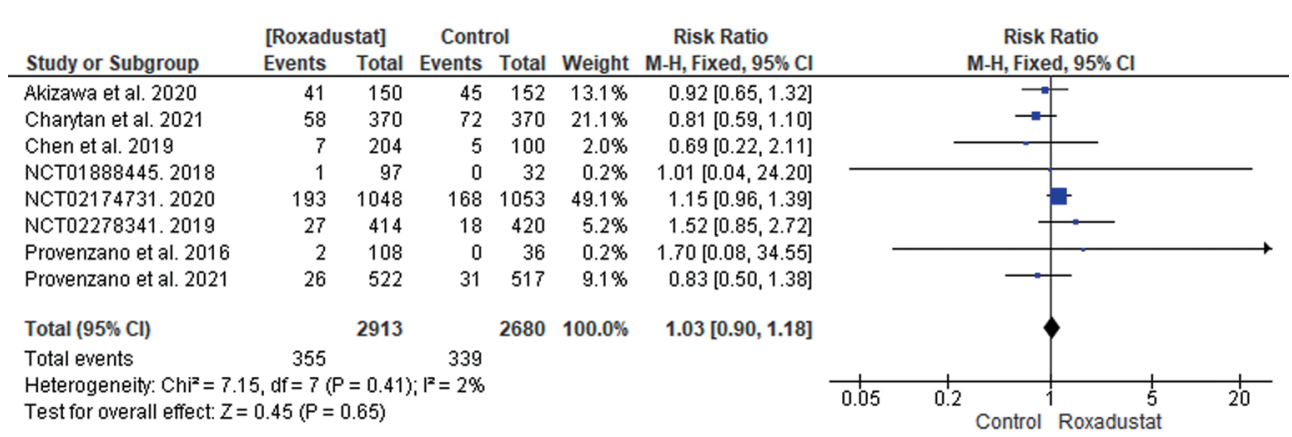

Figure S3 Forest plot of comparison: 2 Adverse effects, outcome: 2.5 Injury, poisoning, and procedural complications.

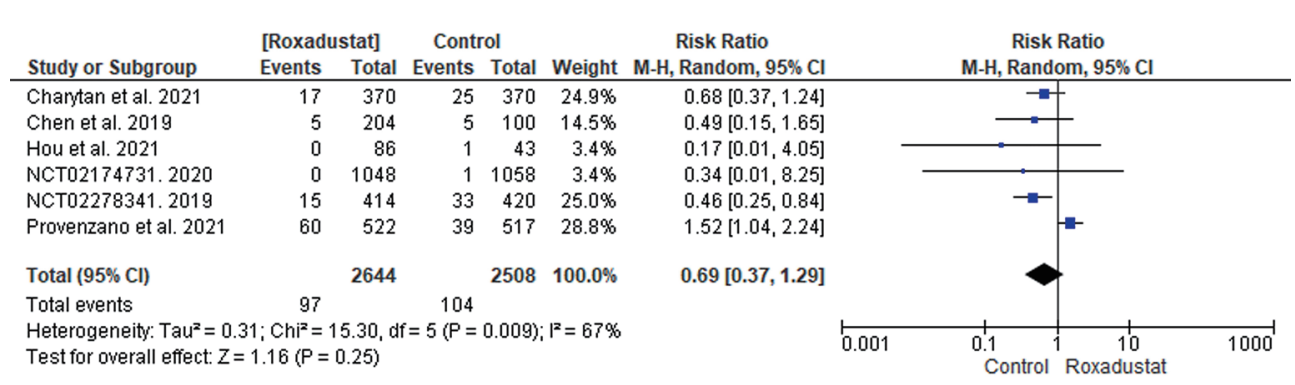

Figure S4 Forest plot of comparison: 2 Adverse effects, outcome: 2.6 Muscle spasm. 


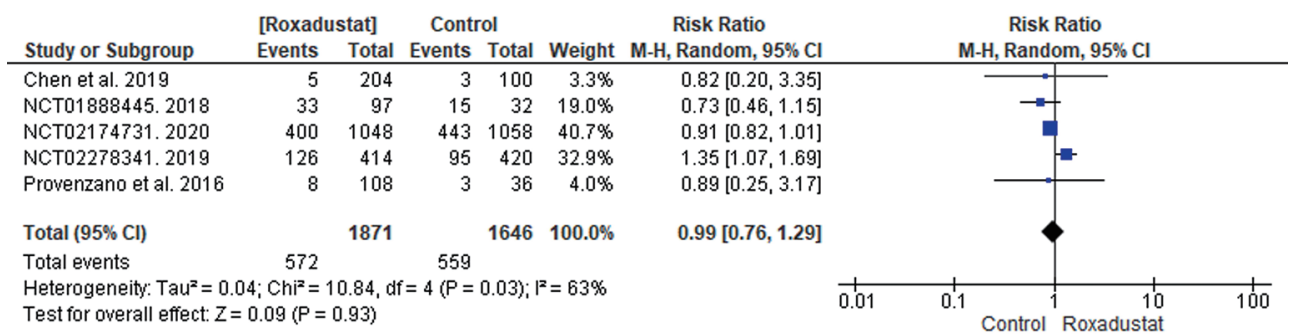

Figure S5 Forest plot of comparison: 2 Adverse effects, outcome: 2.7 Infection or infestation.

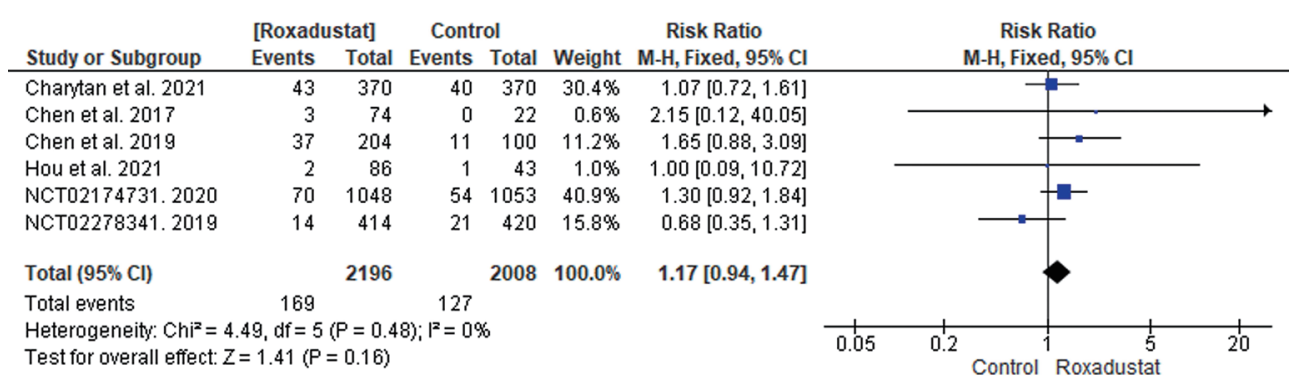

Figure S6 Forest plot of comparison: 2 Adverse effects, outcome: 2.8 Upper respiratory tract infections.

\begin{tabular}{|c|c|c|c|c|c|c|c|c|c|c|}
\hline \multirow[b]{2}{*}{ Study or Subgroup } & \multicolumn{2}{|c|}{ [Roxadustat] } & \multicolumn{2}{|c|}{ Control } & \multicolumn{2}{|r|}{ Risk Ratio } & & \multirow{2}{*}{\multicolumn{2}{|c|}{$\begin{array}{c}\text { Risk Ratio } \\
\text { M-H, Fixed, } 95 \% \mathrm{Cl}\end{array}$}} & \\
\hline & Events & Total & Events & Total & Weight & M-H, Fixed, $95 \% \mathrm{Cl}$ & & & & \\
\hline Charytan et al. 2021 & 62 & 370 & 47 & 370 & $14.6 \%$ & $1.32[0.93,1.87]$ & & & & \\
\hline Chen et al. 2017 & 3 & 74 & 1 & 22 & $0.5 \%$ & $0.89[0.10,8.15]$ & & & & \\
\hline Chen et al. 2019 & 25 & 204 & 16 & 100 & $6.7 \%$ & $0.77[0.43,1.37]$ & & & - & \\
\hline Hou et al. 2021 & 5 & 86 & 3 & 43 & $1.2 \%$ & $0.83[0.21,3.32]$ & & & & \\
\hline NCT02174731.2020 & 85 & 1048 & 85 & 1053 & $26.4 \%$ & $1.00[0.75,1.34]$ & & & & \\
\hline NCT02278341.2019 & 66 & 414 & 75 & 420 & $23.1 \%$ & $0.89[0.66,1.21]$ & & & & \\
\hline Provenzano et al. 2021 & 99 & 522 & 88 & 517 & $27.5 \%$ & $1.11[0.86,1.45]$ & & & & \\
\hline Total $(95 \% \mathrm{Cl})$ & & 2718 & & 2525 & $100.0 \%$ & $1.04[0.90,1.19]$ & & & & \\
\hline Total events & 345 & & 315 & & & & & & & \\
\hline $\begin{array}{l}\text { Heterogeneity: } \mathrm{Chi}^{2}=4 \text {. } \\
\text { Test for overall effect: } Z\end{array}$ & $\begin{array}{l}6, d f=6(f \\
0.49(P=\end{array}$ & $\begin{array}{l}=0.64) \\
0.62)\end{array}$ & $i^{2}=0 \%$ & & & & \begin{tabular}{ll}
0.1 & \multicolumn{1}{c}{0.2}
\end{tabular} & $\begin{array}{l}1.5 \\
\text { Control }\end{array}$ & $\begin{array}{c}1 \\
1 \\
\text { Roxadustat }\end{array}$ & $\overrightarrow{10}$ \\
\hline
\end{tabular}

Figure S7 Forest plot of comparison: 2 Adverse effects, outcome: 2.9 Hypertension.

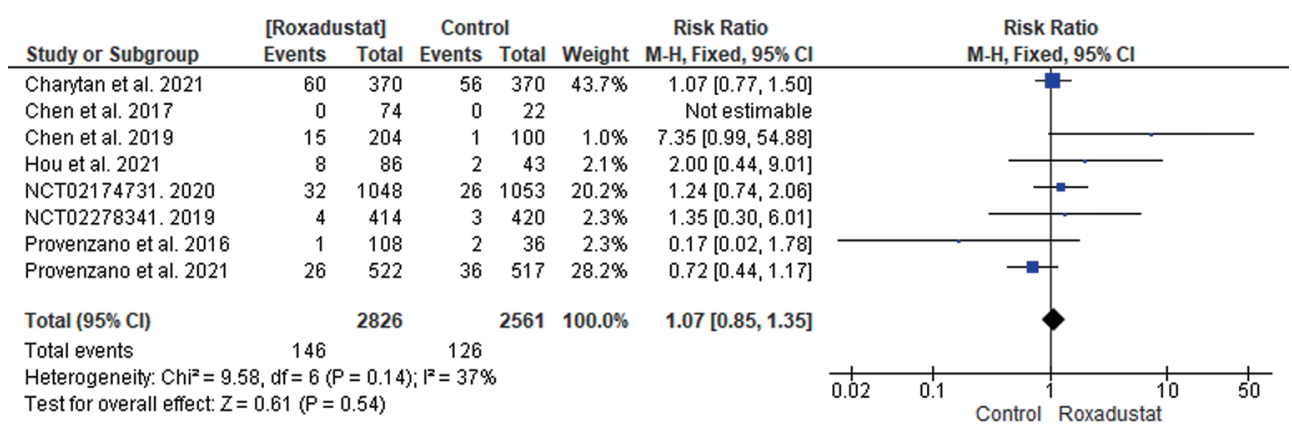

Figure 8 Forest plot of comparison: 2 Adverse effects, outcome: 2.10 Hyperkalemia. 
Table S1 Search terms and results in different databases

\begin{tabular}{|c|c|c|c|}
\hline $\begin{array}{l}\text { Database } \\
\text { name }\end{array}$ & Search terms & Search fields & Result \\
\hline PubMed & (Roxadustat OR ASP1517 OR FG4592 OR “FG-4592”) AND (kidney OR renal) AND (Anemia) & All Field & 104 \\
\hline $\begin{array}{l}\text { Web Of } \\
\text { Science }\end{array}$ & (Roxadustat OR ASP1517 OR FG4592 OR “FG-4592”) AND (kidney OR renal) AND (Anemia) & Topic & 150 \\
\hline Scopus & (Roxadustat OR ASP1517 OR FG4592 OR “FG-4592”) AND (kidney OR renal) AND (Anemia) & Title, Abstract, Keywords & 159 \\
\hline Cochrane & $\begin{array}{l}\text { ((Roxadustat) OR (ASP1517) OR (FG4592) OR (FG-4592)) AND ((kidney) OR (renal)) AND } \\
((\text { Anemia)) }\end{array}$ & Title, Abstract Keyword & 113 \\
\hline Embase & (roxadustat OR asp1517 OR fg4592 OR 'fg 4592') AND (kidney OR renal) AND anemia & All Field & 256 \\
\hline Google & with all of the words: Roxadustat OR FG4592 OR "FG-4592" with at least one of the words: & & 126 \\
\hline Scholar & kidney anemia In the title of the article & & \\
\hline
\end{tabular}

Table S2 The baseline laboratory values of the included patients

\begin{tabular}{|c|c|c|c|c|c|c|}
\hline Study & Group & $\begin{array}{c}\text { Hb level }(g / d L) \\
\text { Mean } \pm S D\end{array}$ & $\begin{array}{l}\text { TSAT }(\%), \\
\text { Mean } \pm \text { SD }\end{array}$ & $\begin{array}{l}\text { Ferritin }(\mathrm{ng} / \mathrm{mL}) \\
\quad \text { Mean } \pm \mathrm{SD}\end{array}$ & $\begin{array}{l}\text { Hepcidin }(\mathrm{ng} / \mathrm{mL}) \\
\text { Mean } \pm \mathrm{SD}\end{array}$ & $\begin{array}{l}\text { TIBC }(\mu \mathrm{g} / \mathrm{dL}) \\
\text { Mean } \pm \mathrm{SD}\end{array}$ \\
\hline \multirow{2}{*}{$\begin{array}{l}\text { Charytan et al. } \\
2021\end{array}$} & Roxadustat & $10.30 \pm 0.66$ & $33.60 \pm 10.10$ & $1002.02 \pm 459.68$ & $272.85 \pm 129.70$ & $201.88 \pm 33.56$ \\
\hline & Epoetin alfa & $10.31 \pm 0.66$ & $33.65 \pm 9.86$ & $959.24 \pm 414.30$ & $270.67 \pm 134.52$ & $202.89 \pm 36.81$ \\
\hline \multirow[t]{2}{*}{ Chen et al. 2017} & Roxadustat & $10.8 \pm 0.7$ & $31.6 \pm 16.7$ & $450.5 \pm 368.2$ & $176.3 \pm 120$ & $217.3 \pm 49.6$ \\
\hline & rhEPO & $10.6 \pm 61.0$ & $34.1 \pm 14.6$ & $458 \pm 361$ & $209.0 \pm 127.1$ & $214 \pm 38$ \\
\hline \multirow[t]{2}{*}{ Chen et al. 2019} & Roxadustat & $10.4 \pm 0.7$ & $33.8 \pm 16.6$ & $498.5 \pm 487.4$ & NR & $264.7 \pm 63.7$ \\
\hline & Epoetin alfa & $10.5 \pm 0.7$ & $30.0 \pm 13.8$ & $420.1 \pm 406.8$ & NR & $269.7 \pm 50.3$ \\
\hline \multirow{2}{*}{$\begin{array}{l}\text { Provenzano et al. } \\
2016\end{array}$} & Roxadustat & $11.2 \pm 0.7$ & $29.2 \pm 10.0$ & $827.7 \pm 474.3$ & $327.1 \pm 178.8$ & $199.7 \pm 34.0$ \\
\hline & Epoetin alfa & $11.2 \pm 1.0$ & $28.1 \pm 14.4$ & $1065.8 \pm 657.2$ & $298.7 \pm 123.1$ & $202.1 \pm 26.7$ \\
\hline \multirow{2}{*}{$\begin{array}{l}\text { Provenzano et al. } \\
2021\end{array}$} & Roxadustat & $8.4 \pm 1.0$ & $27.02 \pm 9.27$ & $441.38 \pm 337.02$ & $173.21 \pm 120.21$ & $241.04 \pm 43.00$ \\
\hline & Epoetin alfa & $8.5 \pm 1.0$ & $27.55 \pm 8.90$ & $436.65 \pm 311.67$ & $169.91 \pm 127.98$ & $238.06 \pm 37.04$ \\
\hline \multirow[t]{2}{*}{ NCT02278341 } & Roxadustat & $10.75 \pm 0.62$ & NR & NR & NR & NR \\
\hline & ESA & $10.77 \pm 0.62$ & NR & NR & NR & NR \\
\hline \multirow[t]{2}{*}{ Hou et al. 2021} & Roxadustat & $9.0 \pm 1.4$ & $31.3 \pm 14.2$ & $268.8 \pm 297.2$ & $142.8 \pm 112.5$ & $237.3 \pm 65.3$ \\
\hline & ESA & $9.0 \pm 1.2$ & $29.6 \pm 13.2$ & $257.4 \pm 190.8$ & $122.0 \pm 82.2$ & $230.6 \pm 83.2$ \\
\hline \multirow[t]{2}{*}{ Nct01888445 } & Roxadustat & $8.84 \pm 0.47$ & $43.66 \pm 16.01$ & $190.20 \pm 187.67$ & NR & $226.2 \pm 35.2$ \\
\hline & $\mathrm{DA}$ & $8.8 \pm 0.51$ & $37.26 \pm 16.06$ & $156.99 \pm 102.49$ & NR & $234.5 \pm 32.9$ \\
\hline \multirow[t]{2}{*}{ Nct02174731 } & Roxadustat & NR & NR & NR & NR & NR \\
\hline & Epoetin alfa & NR & NR & NR & NR & NR \\
\hline \multirow{2}{*}{$\begin{array}{l}\text { Akizawa et al. } \\
2020\end{array}$} & Roxadustat & $11.02 \pm 0.56$ & $28.28 \pm 11.70$ & $102.31 \pm 83.45$ & $26.44 \pm 21.50$ & $242.4 \pm 39.1$ \\
\hline & DA & $11.01 \pm 0.60$ & $29.04 \pm 10.18$ & $96.28 \pm 75.14$ & $24.44 \pm 20.99$ & $242.9 \pm 34.6$ \\
\hline
\end{tabular}

DA, Darbepoetin Alfa; rhEPO, recombinant human erythropoietin; ESA, erythropoiesis-stimulating agent; Hb, hemoglobin; SD, standard deviation; TIBC, total iron-binding capacity; TSAT, transferrin saturation; NR, not reported. 
Table S3 The studies assessed C-reactive protein

\begin{tabular}{|c|c|c|c|}
\hline \multirow{2}{*}{ Study } & \multirow{2}{*}{ Group } & \multicolumn{2}{|c|}{ CRP, Number of patients (\%) } \\
\hline & & $\leq \mathrm{ULN}$ & $>$ ULN \\
\hline \multirow[t]{2}{*}{ Charytan et al. 2021} & Roxadustat & $178(48.1 \%)$ & $189(51.1 \%)$ \\
\hline & Epoetin alfa & $192(51.8 \%)$ & $177(47.7 \%)$ \\
\hline \multirow[t]{2}{*}{ Chen et al. 2019} & Roxadustat & $158(77.5 \%)$ & $46(22.5 \%)$ \\
\hline & Epoetin alfa & $80(80.0 \%)$ & $20(20.0 \%)$ \\
\hline \multirow[t]{2}{*}{ Provenzano et al. 2021} & Roxadustat & $289(55.4 \%)$ & $228(43.7 \%)$ \\
\hline & Epoetin alfa & $289(55.5 \%)$ & $226(43.4 \%)$ \\
\hline \multirow[t]{2}{*}{ Hou et al. 2021} & Roxadustat & $48(56 \%)$ & $38(44 \%)$ \\
\hline & ESA & $25(58 \%)$ & $18(42 \%)$ \\
\hline \multirow[t]{2}{*}{ Akizawa et al. 2020} & Roxadustat & \multicolumn{2}{|c|}{$<$ ULN, $136(90.7 \%) \geq U L N, 14$ (9.3\%) } \\
\hline & DA & \multicolumn{2}{|c|}{$<$ ULN, $129(85.4 \%) \geq U L N, 22(14.6 \%)$} \\
\hline
\end{tabular}

DA, Darbepoetin Alfa; ESA, erythropoiesis-stimulating agent; CRP, C-reactive protein; ULN, upper limit of normal.

Table S4 Publication bias using Egger's regression

\begin{tabular}{|c|c|c|c|c|c|c|}
\hline Outcome & Intercept & Standard error & Lower limit & Upper limit & t-value & P-value \\
\hline Hemoglobin & 1.26 & 1.89 & -3.09 & 5.62 & 0.669 & 0.523 \\
\hline Ferritin & 1.629 & 1.3211 & -1.604 & 4.86 & 1.233 & 0.264 \\
\hline TSAT & 1.382 & 0.7 & -0.33 & 3.1 & 3.1 & 0.1 \\
\hline Hepcidin & -0.43 & 1.4 & -3.84 & 2.99 & 0.306 & 0.77 \\
\hline TIBC & -0.95 & 1.82 & -5.63 & 3.74 & 0.52 & 0.63 \\
\hline Serum Iron & 0.63 & 0.9 & -1.68 & 2.94 & 0.7 & 0.52 \\
\hline Transferrin & 2.46 & 0.574 & -4.833 & 9.76 & 4.29 & 0.146 \\
\hline TEAEs & 0.6 & 0.87 & -0.141 & 2.603 & 0.689 & 0.511 \\
\hline Serious TEAEs & 0.985 & 0.421 & -0.01 & 1.98 & 2.341 & 0.052 \\
\hline
\end{tabular}

TSAT, transferrin saturation; TIBC, total iron-binding capacity; TEAEs, treatment-emergent adverse effects

Table S5 Meta-analysis of the primary outcomes and sensitivity analysis

\begin{tabular}{|c|c|c|c|c|c|c|c|c|c|}
\hline \multirow{2}{*}{ Outcome } & \multirow{2}{*}{$\begin{array}{l}\text { No. of participants } \\
\text { Roxadustat/Control) }\end{array}$} & \multirow{2}{*}{$\begin{array}{l}\text { No. of } \\
\text { trials }\end{array}$} & \multicolumn{4}{|c|}{ Quantitative data synthesis } & \multicolumn{3}{|c|}{ Heterogeneity analysis } \\
\hline & & & SMD & $95 \% \mathrm{Cl}$ & $Z$ value & $P$ value & df & $P$ value & $\mathrm{I}^{2}(\%)$ \\
\hline \multicolumn{10}{|l|}{ Hemoglobin level } \\
\hline All studies & $2896 / 2673$ & 10 & 0.21 & {$[0.02,0.39]$} & 2.22 & 0.03 & 9 & 0.00001 & 89 \\
\hline Omitting Akizawa et al. 2020 & $2782 / 2542$ & 9 & 0.29 & {$[0.12,0.45]$} & 3.43 & 0.0006 & 8 & 0.00001 & 84 \\
\hline Omitting Charytan et al. 2021 & $2526 / 2302$ & 9 & 0.21 & {$[-0.00,0.42]$} & 1.92 & 0.05 & 8 & 0.00001 & 90 \\
\hline Omitting Chen et al. 2017 & $2836 / 2651$ & 9 & 0.18 & {$[-0.01,0.37]$} & 1.87 & 0.06 & 8 & 0.00001 & 90 \\
\hline Omitting Chen et al. 2019 & $2692 / 2573$ & 9 & 0.21 & {$[0.01,0.42]$} & 2.07 & 0.04 & 8 & 0.00001 & 90 \\
\hline Omitting Hou et al. 2021 & $2810 / 2630$ & 9 & 0.10 & {$[-0.04,0.24]$} & 1.40 & 0.16 & 8 & 0.00001 & 79 \\
\hline Omitting NCT01888445. 2018 & $2833 / 2646$ & 9 & 0.23 & {$[0.03,0.42]$} & 2.27 & 0.02 & 8 & 0.00001 & 90 \\
\hline Omitting NCT02174731. 2020 & $1893 / 1657$ & 9 & 0.24 & {$[0.00,0.47]$} & 2.00 & 0.05 & 8 & 0.00001 & 89 \\
\hline Omitting NCT02278341. 2019 & $2483 / 2253$ & 9 & 0.21 & {$[-0.00,0.43]$} & 1.93 & 0.05 & 8 & 0.00001 & 90 \\
\hline Omitting Provenzano et al. 2016 & $2835 / 2651$ & 9 & 0.23 & {$[0.03,0.42]$} & 2.28 & 0.02 & 8 & 0.00001 & 90 \\
\hline Omitting Provenzano et al. 2021 & $2374 / 2152$ & 9 & 0.22 & {$[-0.00,0.45]$} & 1.95 & 0.05 & 8 & 0.00001 & 90 \\
\hline
\end{tabular}

$\mathrm{Cl}$, confidence interval; df, degrees of freedom; SMD, standardized mean difference. 